\title{
Molecular cloning and expression of drought-induced protein 3 (DIP3) encoding a class III chitinase in upland rice
}

\author{
X.L. Guo ${ }^{1}$, L.R. Bai ${ }^{1}$, C.Q. Su ${ }^{1}$, L.R. Shi ${ }^{1}$ and D.W. Wang ${ }^{2}$ \\ ${ }^{1}$ College of Biological Science, Hengshui University, Hengshui, China \\ ${ }^{2}$ State Key Laboratory of Plant Cell and Chromosome Engineering, \\ Chinese Academy of Sciences, Beijing, China \\ Corresponding author: L.R. Bai \\ E-mail: blrrlb@163.com
}

Genet. Mol. Res. 12 (4): 6860-6870 (2013)

Received February 15, 2013

Accepted September 5, 2013

Published December 19, 2013

DOI http://dx.doi.org/10.4238/2013.December.19.5

\begin{abstract}
A drought-induced gene, DIP3, encoding a chitinase III protein was isolated from the roots of upland rice by reverse transcriptionpolymerase chain reaction (RT-PCR). Sequence analysis demonstrated that the cDNA and deduced protein showed high identity to Oryza sativa class III chitinase. The deduced protein contained a signal peptide sequence in the N-terminal region of 21aa and a conserved glycosyl hydrolase (GH) 18 domain. The secondary and 3D structures were analyzed and showed that it contained $\alpha$-helix, $\beta$-sheets, extended strand and random coil structures and that it was approximately spheroidal. Real-time quantitative PCR analysis revealed that expression levels accumulated rapidly under different forms of abiotic stress (drought, salt and low temperature), peaked at different times and then decreased. These results implied that as a member of class III chitinases, DIP3 may function as a stress-induced protein involved in the regulation of plant stress response.
\end{abstract}

Key words: Upland rice; Drought-induced protein 3 (DIP3); Stress; Chitinase III 


\section{INTRODUCTION}

Drought is thought of as one of the most important environmental stresses that impact plant growth and crop productivity (Bernier et al., 2009). A series of changes at the cellular to physiological level occur with low temperature, drought and high salinity (Liu et al., 1998). More and more genes that respond to abiotic stresses have been cloned and identified (Shinozaki and Yamaguchi-Shinozaki, 2000; Chinnusamy et al., 2003; Chen et al., 2011). Previous research has indicated that overexpression of chitinase from Trichoderma harzianum in transgenic tobacco plants confers resistance to heavy metals and high salinity (Dana et al., 2006).

Chitinases (EC3.2.1.14) could catalyze the hydrolytic cleavage of the $\beta-1,4-$ glycosidic bond in N-acetyl-glucosamine biopolymers largely found in chitin (CohenKupiec and Chet, 1998; Kasprzewska, 2003; Jitonnom et al., 2011). They hydrolyze the deacetylation of chitin so as to be referred to as chitosan (Tanabe et al., 2000). One of the physiological roles of chitinases in plants is to protect plants against fungal pathogens by degrading chitin (Schlumbaum et al., 1986). Some other chitinases do not show any antifungal activities (Taira et al., 2005). Chitinases also respond to abiotic stress either in growth or developmental processes (Collinge et al., 1993; Kasprzewska, 2003; Collinge et al., 2008; Sharma et al., 2011).

Chitinases are divided into seven classes (I-VII) according to their structure, substrate specificity, mechanism of catalysis, and sensitivity to inhibitors (Arie et al., 2000). Chitinases have some domains based on their amino acid sequences. Typical plant chitinases have an N-terminal signal region, a main structural domain (or a catalytic domain), and a $\mathrm{C}$-terminal region that exists only in vacuolar chitinases. The characteristic catalytic domain is called the glycosyl hydrolase (GH) domain, which consists of about 220 to 230 amino acid residues (Liu et al., 2010). The catalytic domain is grouped into two families: glycosyl hydolase family 18 (GH18) and glycosyl hydrolase family 19 (GH19) (Li and Greene, 2010). Chitinases belong to the GH18 family including class III and V chitinases (Takenaka et al., 2009). The GH19 family is exclusively composed of the chitinases of class I, II, and IV members (Santos et al., 2008). Different structure and roles of plant chitinases had been found during plant evolution. Till now, several genes encoding chitinases have been cloned from many plants (Fortunato et al., 2007; Baranski et al., 2008; Ganesan et al., 2009; Liu et al., 2010; Taira et al., 2011). Several plant chitinases are constitutive, developmentally regulated and tissue- or organ-specific. It appears that the role of plant chitinases is not solely in defense against pathogen attack (Kasprzewska, 2003). In addition, their functions seem to differ between plants (Onaga and Taira, 2008).

To date, there is no report about chitinases in upland rice. We believe that research on chitinase structure and physiology in upland rice will probably lead to a better understanding of the response of chitinases to drought. On the basis of obtaining a protein named DIP3 (drought-induced protein 3) similar to chitinase (EC 3.2.1.14) III protein by NCBI blasting, which expressed differently in upland rice under drought stress using proteome analysis (data not shown), we cloned the DIP3 gene encoding a class III chitinase. At the same time, we studied expression patterns of the DIP3 gene in different stresses. The results may provide a theoretical basis for understanding the mechanisms of upland abiotic stress and also pave the way for generating stress-tolerant plants through a genetic engineering approach. 


\section{MATERIAL AND METHODS}

\section{Plant materials}

Upland rice (Oryza sativa) was germinated in the dark for 3 days at $28^{\circ} \mathrm{C}$, and the seedlings grown in nutrient solution at a photon flux density of 300-350 mol m-2s-1, with $60-80 \%$ relative humidity, 12 -h light $/ 12$-h dark day-night cycle and $28^{\circ} \mathrm{C}$ temperature in a phytotron (Lian et al., 2006). Four-week-old plants were used for the different treatments. Cold treatment was performed at $4{ }^{\circ} \mathrm{C}$ as opposed to the control at $28^{\circ} \mathrm{C}$. For salt or drought stresses, plants were treated with $1.5 \% \mathrm{NaCl}$ or $20 \%$ PEG 6000 in nutrient solution, whereas the control was treated with nutrient solution. The roots were harvested at $0,1,2,5,10$, and $24 \mathrm{~h}$, respectively. All samples were frozen in liquid nitrogen and stored at $-80^{\circ} \mathrm{C}$ for further analysis.

\section{RNA extraction}

Total RNA was isolated from the roots using TRIzol reagent (Promega, USA). Total RNA was checked for quality, integrity and concentration by $1 \%$ agarose gel electrophoresis.

\section{First-strand cDNA synthesis}

The first-strand cDNA of all the eighteen samples were synthesized in $20 \mu \mathrm{L}$ reverse transcription volume with approximately $1 \mu \mathrm{g}$ total RNA from each sample using oligo dT 15 primer in Reverse Transcription System (Promega, USA) following manufacturer protocol.

\section{Cloning and sequencing}

DIP3 coding region was amplified with the primer pairs (DIP3-1: 5'-ATGGCGTCC CGACGCC-3' and DIP3-2: TCACAGAACCTGATCCAGGAGAC). PCR products were purified with the Axygen purification kit (Axygen Agro-tech Co. Ltd., Hangzhou, China) and then cloned to pMD20-T vector (TaKaRa, Japan). Sequence was confirmed by Sunbio-tech Co. Ltd. and checked for similarity by blasting against sequences in the GenBank database.

The PCR reaction was performed in My CyclerTM Thermal Cycler (Bio-Rad Laboratories Ltd., USA) with one step of $5 \mathrm{~min}$ at $94^{\circ} \mathrm{C}, 35$ cycles of $30 \mathrm{~s}$ at $94^{\circ} \mathrm{C}, 30 \mathrm{~s}$ at $55^{\circ} \mathrm{C}$, and $60 \mathrm{~s}$ at $72^{\circ} \mathrm{C}$, and a last step of $7 \mathrm{~min}$ at $72^{\circ} \mathrm{C}$.

\section{Bioinformatics analysis}

The nucleotide sequence analysis, amino acid sequence prediction and multiple sequence alignment were performed by DNAMAN 5.0. Physical and chemical parameters of protein were determined using ProtParam tool (http://www.expasy.org/tools/protparam.html). Hydrophobicity analysis was performed on ProtScale (http://www.expasy.org/cgi-bin/protscale.pl), and transmembrane topology prediction was performed using TMHMM Server version 2.0 (http:// www.cbs.dtu.dk/services/TMHMM/). The signal peptide was predicted using SignalP 3.0 Server (http://www.cbs.dtu.dk/services/SignalP/). Subcellular localization was predicted by the PSORT tool (http://wolfpsort.seq.cbrc.jp/). The secondary structure was analyzed using NPSA (http:// 
npsa-pbil.ibcp.fr/cgi-bin/npsa_automat.pl?page=/NPSA/npsa_sopma.html). The 3D structure was predicted by SWISS-MODEL Workspace (http://swissmodel.expasy.org/workspace/index. php?func=modelling_simple1). The phylogenetic tree was constructed with MEGA5.05.

\section{Gene expression analysis}

The synthetic cDNA from $1 \mu \mathrm{g}$ of eighteen treated RNA were used as the templates for DIP3 gene expression analysis. The primer pair (forward: 5'-CCTCTACACCACCGTCA TCATCT-3'; reverse: 5'-TGGCAGTGCTTGATGTCGG-3') for DIP3 gene was designed. The house-keeping actin gene (GenBank, accession No. X16280.1) was used as the internal standard. The primer pair (forward: 5'-ACCATTGGTGCTGAGCGTTT-3'; reverse: 5'-CGCAG CTTCCATTCCTATGAA-3') for actin gene was designed. All real-time PCR assays were carried out in a $20-\mu \mathrm{L}$ volume with $2 \mu \mathrm{L}$ cDNA temple, $10 \mu \mathrm{L} \mathrm{SYBR}^{\circledR}$ Premix Ex Taq $^{\mathrm{TM}}$ (Perfect Real Time) (TaKaRa, Japan), 0.4 $\mu \mathrm{L}$ 50X Rox Reference Dye, $0.4 \mu \mathrm{L}, 10 \mu \mathrm{M}$ each primer and DNase-free water to a final volume of $20 \mu \mathrm{L}$. All quantitative reactions were carried out using ABI PRISM 7500 (Applied Biosystems, Foster City, CA, USA) with the program as follows: $30 \mathrm{~s}$ at $95^{\circ} \mathrm{C}$ and 40 cycles of $5 \mathrm{~s}$ at $95^{\circ} \mathrm{C}$ and $34 \mathrm{~s}$ at $60^{\circ} \mathrm{C}$. The relative quantification of RNA expression was evaluated using the comparative $-\Delta \Delta \mathrm{Ct}$ method employing the formula relative expression $=2-[\Delta \mathrm{Ct}$ sample- $\Delta \mathrm{Ct}$ control $]$ (Livak and Schmittgen, 2001).

\section{RESULTS}

\section{Cloning and sequencing of DIP3}

A 894-bp DIP3 cDNA sequence was amplified using DIP3-1 and DIP3-2 primers from cDNA synthesized from total RNA (Figure 1). The sequence was submitted to GenBank of the National Center for Biotechnology Information (NCBI) with accession No. JQ218437. Sequence analysis showed that DIP3 cDNA contained an open reading frame (ORF) (Figure 2).

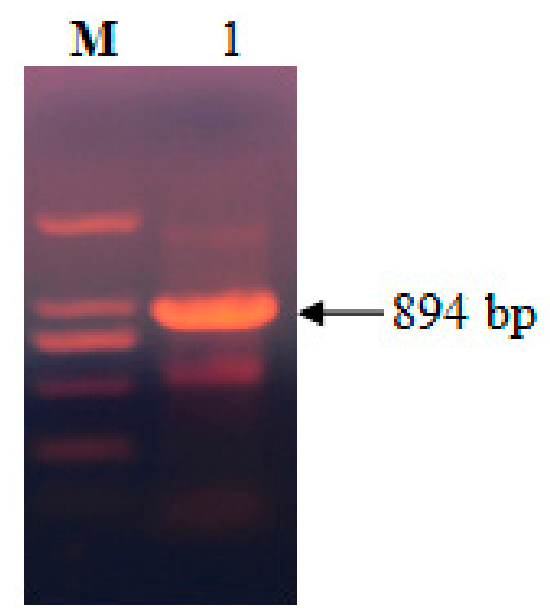

Figure 1. cDNA fragment of DIP3 produced by RT-PCR. Lane M=DL 2000 marker (Six bands with 100, 250, 500, 750, 1000, $2000 \mathrm{bp);} \mathrm{lane} 1$ = RT-PCR produce. 


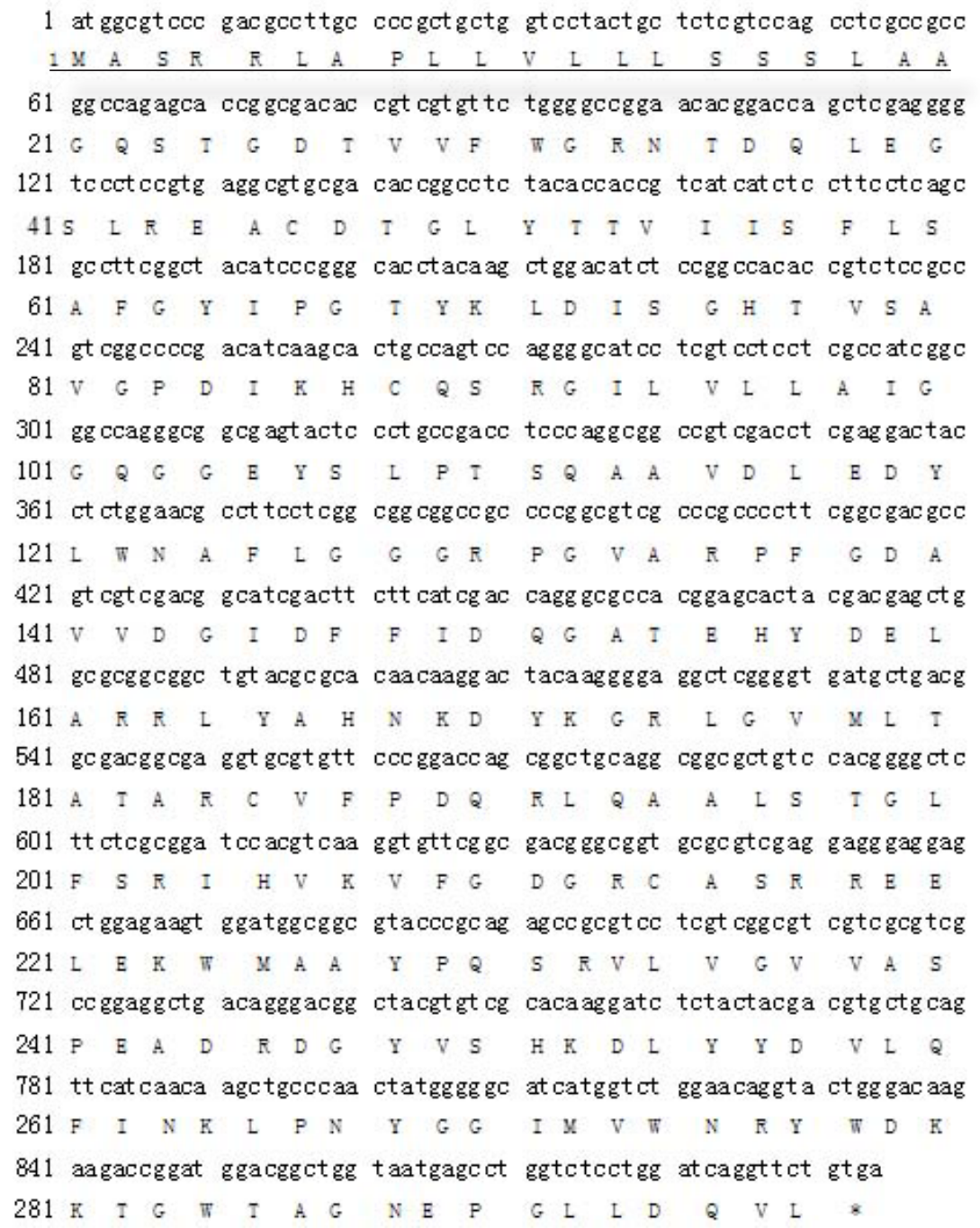

Figure 2. Nucleotide and deduced amino acid sequences of DIP3 cDNA. The putative signal peptide at the $\mathrm{N}$-terminal is underlined.

Homology analysis using BLAST of GenBank showed that the DIP3 cDNA shared $59 \%$ identity with $O$. sativa class III chitinase homologue OsChib3H-a (AB027420.1), as well as $32 \%$ identity with $O$. sativa mRNA for class III chitinase homologue OsChib3H-h (AB027427.1). Therefore, we speculated that DIP3 may encode a gene of class III chitinase of upland rice.

\section{Sequence analysis of upland rice DIP3}

Amino acid sequence was deduced from the cDNA sequence (Figure 2). The putative 
DIP3 protein had 297 amino acids with a predicted molecular weight of $32.5489 \mathrm{kD}$ and $\mathrm{pI} 6.08$. The instability index (II) was computed to be 41.86 , which classified the protein as unstable. The conserved domain of DIP3 protein contained a conserved glycosyl hydrolase (GH) 18 domain and belonged to the chitinase superfamily. A signal peptide sequence was identified in the $\mathrm{N}$ terminal region of 21 amino acids, which could indicate that it is a secretory protein. However, it lacked the chitin binding domain (CBD) in the $\mathrm{N}$-terminal region. A previous report showed that $\mathrm{CBD}$ consisted of a highly-conserved, cysteine-rich region of approximately 40 amino acid residues (Graham and Sticklen, 1994). Transmembrane region analysis of Sequence Exp number of AAs in TMHs indicated that DIP3 protein was not a transmembrane protein. It was located in the cytoplasm by subcellular localization. Hydrophobicity region analysis indicated a weak hydrophobic nature, which could predict that it was a soluble protein.

The secondary structure of DIP3 protein analyzed by NPSA showed that it contained $\alpha$-helix (30.98\%), $\beta$-sheet (7.41\%), extended strand (20.20\%), and random coil $(41.41 \%)$ structures. The 3D structure analysis predicted that the protein contained nine $\beta$-sheets, eight $\alpha$-helixes, and one random coil (Figure 3 ). The protein was approximately spheroidal, which formed a special spatial structure to play a physiological activity.

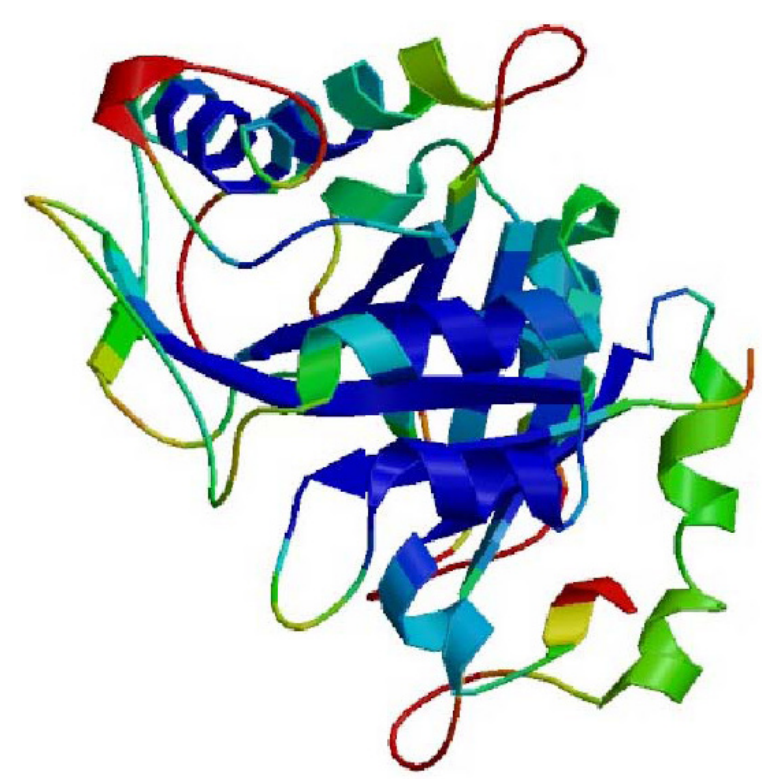

Figure 3. Three-dimensional structure of DIP3 was predicted. The color gradient from blue (more reliable regions) to red (potentially unreliable regions).

Homology analysis using GenBank BLAST showed that the amino acid sequence of DIP3 had the highest similarity with $O$. sativa chitinase (EC 3.2.1.14) III (AAX95331.1). Phylogenic analysis of DIP3 protein indicated that the different chitinases originated from the same ancestor in evolutionary history (Figure 4). DIP3 protein shared the highest homology with Nicotiana tabacum basic chitinase III and Rehmannia glutinosa acidic chitinase III proteins. The frequencies of amino acid residues were calculated for DIP3 protein (Table 1). Compared with the class III chitinases, similar frequencies of DIP3 amino acid residues were obtained. 


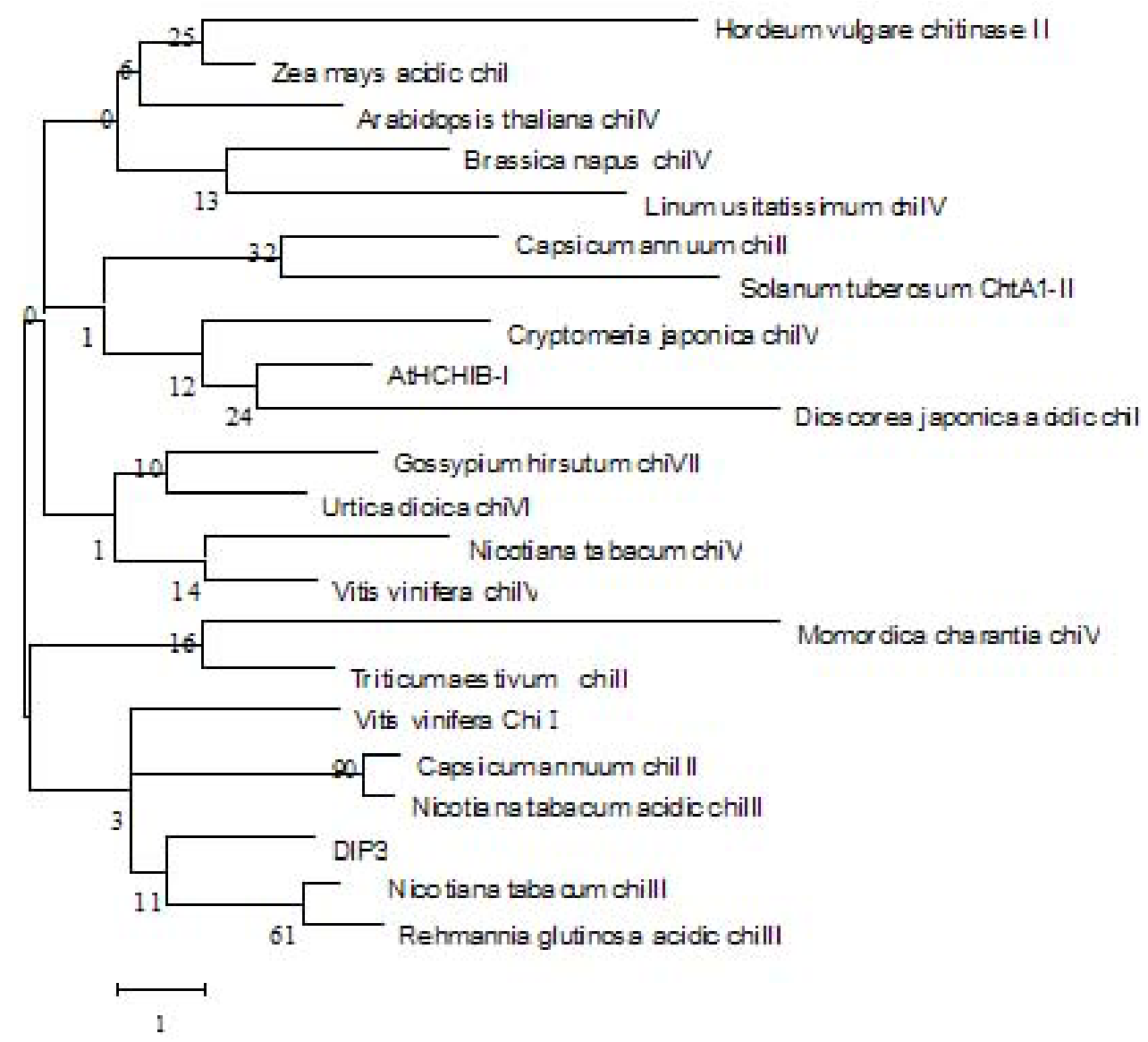

Figure 4. Phylogenic analysis of chitinase proteins. The phylogenic tree is based on an alignment of the following proteins reported in GenBank: AtHCHIB-I (NP_566426), Zea mays acidic chil (AAA62421), Dioscorea japonica acidic ChiI (AAB23692), Vitis vinifera ChiI (AAD04295); Triticum aestivum chiII (AAX83262), Capsicum annuum chiII (AAC36359), Hordeum vulgare chitinase II (CAB99486), Solanum tuberosum ChtA1-II (AAB96340); Capsicum annuum chiIII (AAN37391), Nicotiana tabacum acidic chiIII (CAA77656), Nicotiana tabacum basic chiIII (CAA77657), Rehmannia glutinosa acidic chiIII (AAO47731); Arabidopsis thaliana chiIV (CAA74930), Brassica napus chiIV (AAB01665), Linum usitatissimum chiIV (ABA39179), Cryptomeria japonica chiIV (BAD77932), Vitis vinifera chilV (AAM95447); Nicotiana tabacum chiV (CAA54373), Momordica charantia chiV (AAM18075); Urtica dioica chiVI (P11218); Gossypium hirsutum chiVII (AAP80801).

Table 1. Frequency of amino acid residues.

\begin{tabular}{|c|c|c|c|c|c|c|c|c|c|c|c|c|c|c|c|c|c|c|c|c|}
\hline Cluster & Ala & Cys & Asp & Glu & Phe & Gly & His & Ile & Lys & Leu & Met & Asn & Pro & Gln & Arg & Ser & Thr & Val & Trp & Tyr \\
\hline & 124 & 4.1 & 5.1 & 3.0 & 4.7 & 12.1 & 1.4 & 3.3 & 2.6 & 5.6 & 1.4 & 4.6 & 64 & 4.1 & 5.1 & 6.6 & 6.0 & 5.0 & 2.1 & 4.7 \\
\hline II & 11.6 & 0.5 & 58 & 3.6 & 6.6 & 7.8 & 1.4 & 58 & 3.4 & 64 & 1.3 & 5.7 & 5.1 & 4.0 & 2.8 & 6.5 & 6.4 & 89 & 1.5 & 5.2 \\
\hline III & 95 & 1.7 & 65 & 2.4 & 4.1 & 10.9 & 2.2 & 4.3 & 4.1 & 9.6 & 1.7 & 4.3 & 4.1 & 3.4 & 53 & 7.1 & 4.6 & 68 & 2.2 & 53 \\
\hline V & 10.7 & 1.0 & 6.4 & 3.6 & $\mathbf{5 . 0}$ & 7.2 & 1.6 & 4.6 & 4.6 & 75 & 13 & 4.1 & 4.7 & 2.5 & 3.5 & 103 & 63 & 7.0 & 2.6 & 5.6 \\
\hline DIP3 & 88 & 1.3 & 7.0 & 3.7 & 3.4 & 11.1 & 2.0 & 4.0 & 3.0 & 11.4 & 13 & 2.4 & 3.7 & 3.7 & 64 & 6.4 & 5.1 & 7.7 & 2.0 & 4.4 \\
\hline
\end{tabular}

The black bold numbers indicate the frequency $\geq 5.0$. The frequency of amino acid residues of I, II,III and V were cited (Xu et al, 2007). 
On the basis of the above results, we predicted that DIP3 protein belonged to O. sativa class III chitinase.

\section{Expression analysis in different stress}

To examine the expression patterns in different environmental stresses, the DIP3 transcripts were determined by real-time quantitative PCR to determine their stress responses. Real-time PCR was performed using cDNA from total RNA obtained from roots under different environmental stresses as shown in Figure 5. Real-time PCR analysis showed that DIP3 was expressed at a certain level in the sample control. After being exposed to low temperature $\left(4^{\circ} \mathrm{C}\right)$, salt $(\mathrm{NaCl})$ and drought (PEG-6000) stresses, the transcript levels changed greatly. For salt stress, the transcript level increased rapidly, reached a peak level at $1 \mathrm{~h}$, decreased slowly from 2 to $5 \mathrm{~h}$, and decreased to the lowest level at $10 \mathrm{~h}$ (Figure 5A). For drought stress, it increased rapidly and was up to peak at $2 \mathrm{~h}$, and thereafter decreased to the lowest at $24 \mathrm{~h}$ (Figure 5B). The expression of DIP3 under cold stress increased reaching a peak at 5 h. At 24 $\mathrm{h}$, it reached the lowest point which was about 1/17 times the highest expression level (Figure 5C). It should be noted that DIP3 expression levels from roots treated with different stresses were first upregulated and then downregulated.

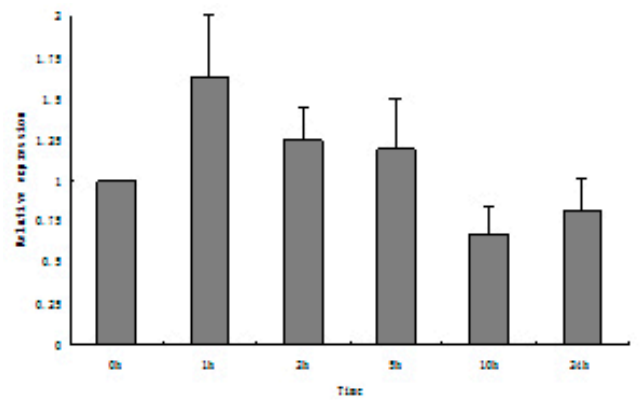

A

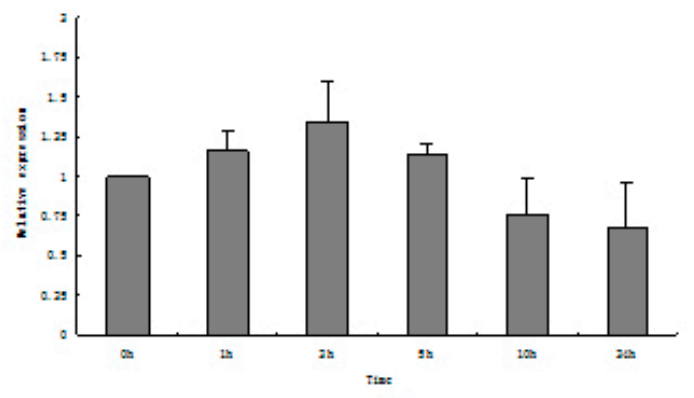

B

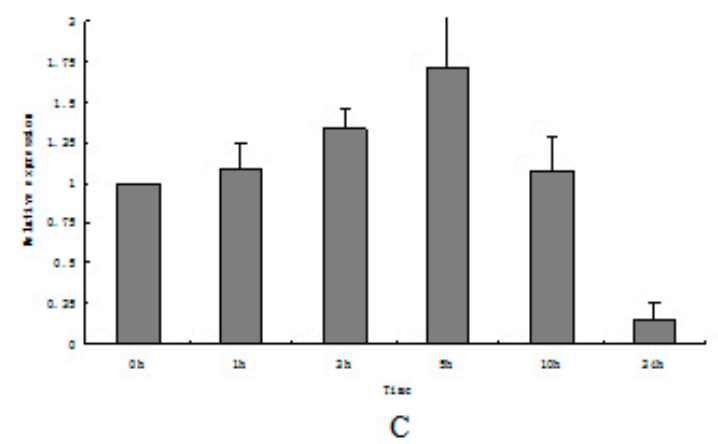

Figure 5. Expression patterns of DIP3 gene in different stress. A. Salt stress. B. Drought stress. C. Cold stress.

\section{DISCUSSION}

Typical plant chitinases have an N-terminal signal region, a main structural 
domain and a C-terminal region that exists only in vacuolar chitinases (Ouyang et al., 2001). Melchers et al. (1994) found that class III chitinases were similar to fungal and bacterial chitinases and did not possess CBD. In this study, a member named DIP3 from the plant chitinase gene family was isolated and characterized from upland rice (O. sativa) hybridization. DIP3 shared the highest identity with plant chitinase III. Sequence analysis showed that the putative protein contained a conserved GH18 domain that belonged to the chitinase superfamily and an N-terminal signal region of 21 aa. However, there was no $\mathrm{C}$-terminal region and also no typical chitin binding domain (CBD) in the N-terminal region. In addition, the soluble extracellular-secreted proteins show the presence of an $\mathrm{N}$-terminal signal peptide, the absence of transmembrane domains and localization signal to target the protein to mitochondria or other intracellular organelles (Lee et al., 2003). Most plant chitinases are endochitinases, which can cut randomly inside the polymer. Bioinformatics analysis of DIP3 revealed that it is localized in the cytoplasm and lacks transmembrane domains, so it belongs to a soluble-secreted endochitinases.

Chitinases are induced by a range of different abiotic stresses such as osmotic, salt, cold, wounding and heavy metals (Van Loon et al., 2006; Pulla et al., 2011). Chitinase activity is induced in Arabidopsis by UV light, heat shock and wounding (Lima et al., 2002). Class I and IV chitinase genes are expressed in most organs of Arabidopsis under normal growth conditions, while class III gene is expressed exclusively when the plants are exposed to environmental stresses, especially salt and wound stresses (Takenaka et al., 2009). In this study, as a gene of class III chitinase, DIP3 levels changed under different stresses. In the beginning, the expression levels were obviously up and then down because of stresses and levels at 1-5 $\mathrm{h}$ were higher than in control. However, the times for reaching each peak level were obviously different. Therefore, we concluded that DIP3 may play a role in the regulation of gene expression under abiotic stress in upland rice and that the mechanism of DIP3 responding to different environment stresses was changed, furthermore implying that the same chitinase class in different plants differ in gene expression and regulation.

In addition, drought tolerance involves adaptation to growth under reduced water potential and the concomitant restructuring of the cell wall allows the growth processes to occur at lower water contents (Moore et al., 2008). In Arabidopsis, expression of a specific chitinase member gene is highly correlated with secondary wall formation (Johnston et al., 2006). In the present study, the expression level of DIP3 protein obtained in roots of upland rice was up in a short time under drought tolerance. Thus, we speculated that DIP3 may respond to plant stresses and play roles in cell wall formation or maintaining the normal function of the plant cell wall under stress conditions. For DIP3, a member of class III chitinases, some information about physiological function and accurate location, for example, will be thoroughly researched.

\section{Conflicts of interest}

The authors declare no conflict of interest.

\section{ACKNOWLEDGMENTS}

Research supported by the National Science Foundation of Hebei Province, China (\#C2010001995). 


\section{REFERENCES}

Arie M, Hikichi K, Takahashi K and Esaka M (2000). Characterization of a basic chitinase which is secreted by cultured pumpkin cells. Physiol. Plantarum 110: 232-239.

Baranski R, Klocke E and Nothnagel T (2008). Chitinase CHIT36 from Trichoderma harzianum enhances resistance of transgenic carrot to fungal pathogens. J. Phytopathol. 156: 513-521.

Bernier J, Serraja R, Kumara A, Venuprasad R, et al. (2009). The large-effect drought-resistance QTL qt112.1 increases water uptake in upland rice. Field Crops Res. 110: 139-146.

Chen H, Zhang B, Hicks LM and Xiong L (2011). A nucleotide metabolite controls stress-responsive gene expression and plant development. PLoS One 6: e26661.

Chinnusamy V, Ohta M, Kanrar S, Lee BH, et al. (2003). ICE1: a regulator of cold-induced transcriptome and freezing tolerance in Arabidopsis. Genes Dev. 17: 1043-1054.

Cohen-Kupiec R and Chet I (1998). The molecular biology of chitin digestion. Curr. Opin. Biotechnol. 9: 270-277.

Collinge DB, Kragh KM, Mikkelsen JD, Nielsen KK, et al. (1993). Plant chitinases. Plant J. 3: 31-40.

Collinge DB, Lund OS and Thordal-Christensen H (2008). What are the prospects for genetically engineered, disease resistant plants? Eur. J. Plant Pathol. 121: 217-231.

Dana M, Pintor-Toro JA and Cubero B (2006). Transgenic tobacco plants overexpressing chitinases of fungal origin show enhanced resistance to biotic and abiotic stress agents. Plant Physiol. 142: 722-730.

Fortunato A, Santos P, Graça I, Gouveia MM, et al. (2007). Isolation and characterization of cgchi3, a nodule-specific gene from Casuarina glauca encoding a class III chitinase. Physiol. Plantarum 130: 418-426.

Ganesan M, Bhanumathi P, Kumari KG, Prabha AL, et al. (2009). Transgenic Indian cotton (Gossypium hirsutum) harboring rice chitinase gene (ChilI) confers resistance to two fungal pathogens. Am. J. Biochem. Biotechnol. 5: 63-74.

Graham LS and Sticklen MB (1994). Plant chitinases. Can. J. Bot. 72: 1057-1083.

Jitonnom J, Lee VS, Nimmanpipug P, Rowlands HA, et al. (2011). Quantum mechanics/molecular mechanics modeling of substrate-assisted catalysis in family 18 chitinases: conformational changes and the role of Asp142 in catalysis in ChiB. Biochemistry 50: 4697-4711.

Johnston MD, Hamberger BR, Friedmann M and Douglas CJ (2006). Functional genomics of plant chitinase-like genes: role in primary and secondary cell wall formation. ASPB abstract 2006. No. P18041.

Kasprzewska A (2003). Plant chitinases - regulation and function. Cell. Mol. Biol. Lett. 8: 809-824.

Lee SA, Wormsley S, Kamoun S, Lee AF, et al. (2003). An analysis of the Candida albicans genome database for soluble secreted proteins using computer-based prediction algorithms. Yeast 20: 595-610.

Li H and Greene LH (2010). Sequence and structural analysis of the chitinase insertion domain reveals two conserved motifs involved in chitin-binding. PLoS One 5: e8654.

Lian HL, Yu X, Lane D, Sun WN, et al. (2006). Upland rice and lowland rice exhibited different PIP expression under water deficit and ABA treatment. Cell Res. 16: 651-660.

Lima VM, Magioli C, Gerhardt LB, Tarre E, et al. (2002). Bean class IV chitinase promoter is modulated during plant development and under abiotic stress. Plant Physiol. 116: 512-521.

Liu GD, Qin YQ, Wei XM and Qu YB (2010). Characterization of the endoglucanase and glucomannanase activities of a glycoside hydrolase family 45 protein from Penicillium decumbens. J. Gen. Appl. Microbiol. 56: 223-229.

Liu Q, Kasuga M, Sakuma Y, Abe H, et al. (1998). Two transcription factors, DREB1 and DREB2, with an EREBP/ AP2 DNA binding domain separate two cellular signal transduction pathways in drought- and low-temperatureresponsive gene expression, respectively, in Arabidopsis. Plant Cell 10: 1391-1406.

Livak KJ and Schmittgen TD (2001). Analysis of relative gene expression data using real-time quantitative PCR and the 2(-Delta Delta C(T)). Methods 25: 402-408.

Melchers LS, Apotheker-de GM, van der Knaap JA, Ponstein AS, et al. (1994). A new class of tobacco chitinases homologous to bacterial exo-chitinases displays antifungal activity. Plant J. 5: 469-480.

Moore JP, Vicre-Gibouin M, Farrant JM and Driouich A (2008). Adaptations of higher plant cell walls to water loss: drought vs desiccation. Physiol. Plant 134: 237-245.

Onaga S and Taira T (2008). A new type of plant chitinase containing LysM domains from a fern (Pteris ryukyuensis): roles of LysM domains in chitin binding and antifungal activity. Glycobiology 18: 414-423.

Ouyang SW, Zhao KJ and Feng LX (2001). The structure and function, classification and evolution of plant chitinase. Chin. Bull. Bot. 18: 418-426.

Pulla RK, Lee OR, In JG, Parvin S, et al. (2011). Identification and characterization of class I chitinase in Panax ginseng C. A. Meyer. Mol. Biol. Rep. 38: 95-102.

Santos P, Fortunato A, Ribeiro A and Pawlowski K (2008). Chitinases in root nodules. Plant Biotechnol. 25: 299-307.

Schlumbaum A, Mauch F, Vögeli U and Boller T (1986). Plant chitinases are potent inhibitors of fungal growth. Nature 
324: 365-367.

Sharma N, Sharma KP, Gaur RK and Gupta VK (2011). Role of plant chitinases in plant defense. Asian J. Biochem. 6 : 29-37.

Shinozaki K and Yamaguchi-Shinozaki K (2000). Molecular responses to dehydration and low temperature: differences and cross-talk between two stress signaling pathways. Curr. Opin. Plant Biol. 3: 217-223.

Taira T, Toma N and Ishihara M (2005). Purification, characterization, and antifungal activity of chitinases from pineapple (Ananas comosus) leaf. Biosci. Biotechnol. Biochem. 69: 189-196.

Taira T, Mahoe Y, Kawamoto N, Onaga S, et al. (2011). Cloning and characterization of a small family 19 chitinase from moss (Bryum coronatum). Glycobiology 21: 644-654.

Takenaka Y, Nakano S, Tamoi M, Sakuda S, et al. (2009). Chitinase gene expression in response to environmental stresses in Arabidopsis thaliana: chitinase inhibitor allosamidin enhances stress tolerance. Biosci. Biotechnol. Biochem. 73: 1066-1071.

Tanabe T, Kawase T, Watanabe T, Uchida Y, et al. (2000). Purification and characterization of a 49-kDa chitinase from Streptomyces griseus HUT 6037. J. Biosci. Bioeng. 89: 27-32.

Van Loon LC, Rep M and Pieterse CM (2006). Significance of inducible defense-related proteins in infected plants. Annu. Rev. Phytopathol. 44: 135-162.

Xu FH, Fan CM and He YQ (2007). Chitinases in Oryza sativa ssp. japonica and Arabidopsis thaliana. J. Genet. Genomics 34: $138-150$. 